\title{
IMPACT OF BREAST CONSERVATION SURGERY VERSUS THE MODIFIED RADICAL MASTECTOMY ON THE QUALITY OF LIFE AMONG BREAST CANCER SURVIVORS IN PAKISTAN
}

\author{
Mumtaz Ahmed, Namrah Mahmood, Shaista Zafar, Umbar Rafique, Moiz Ahmed*, Kiran Abbas* \\ Pakistan Institute of Medical Sciences, Islamabad Pakistan, *Jinnah Postgraduate Medical Centre, Karachi Pakistan
}

\begin{abstract}
Objective: To compare quality of life (QoL) of patients who received Breast conservation surgery (BCS) to those who underwent Mastectomy.

Study Design: A comparative study.

Place and Duration of Study: The study took place at Pakistan Institute of Medical Sciences, Islamabad, from Aug 2018 to Sep 2019.

Methodology: A comparative study using non probability sampling technique was conducted at Pakistan Institute of Medical Sciences. Quality of life was assessed using a QOL-CSV to evaluate the physical, psychological, social, spiritual well-being as well as distress and fear factors. Data was analyzed using SPSS software 20 and chi square test was applied.

Results: Out of a total of 50 cases with mean age of $50.14 \pm 4.8$ years in Breast conservation group (BCS) and 166 cases with mean age of $54.7 \pm 6.3$ years were there in mastectomy group. In BCS group there were moderate scores in physical, social, and psychological well-being as well as in fear factor and distress of diagnosis. No comparable difference was observed between both groups with respect to physical, psychological, or spiritual wellbeing, distress score and fear factor. However significant difference was found in the quality of life regarding social concerns.

Conclusion: Breast conservation surgery was associated with significant improvements in quality of life scores in terms of social and psychological well-being, with comparable physical and spiritual wellbeing in study population.
\end{abstract}

Keywords: Breast conservation surgery, Mastectomy, Quality of life.

This is an Open Access article distributed under the terms of the Creative Commons Attribution License (http://creativecommons.org/licenses/by/4.0), which permits unrestricted use, distribution, and reproduction in any medium, provided the original work is properly cited.

\section{INTRODUCTION}

According to recent reports, Pakistan has the highest rate of Breast Cancer compared to other Asian countries with approximately one million new cases being reported annually; out of these about forty thousand patients die $^{1}$. It is further speculated that about every ninth women will be expected to develop breast cancer at least once in her life 2 . Earlier data showed that breast cancer was the most frequent cause of cancer in females in Pakistan, accounting for about one-third of the overall cancers ${ }^{3}$. A recent study reported that breast cancer accounts for approximately 49.5\% of all cancers in women in Karachi, the largest city of Pakistan 4 .

Correspondence: Dr Moiz Ahmed, Department of General Surgery, JPMC, Karachi Pakistan

Received: 23 Mar 2020; revised received: 27 Aug 2020; accepted: 14 Oct 2020
Current progress and development in the diagnosis and the management of breast cancer, it is still associated with substantial morbidity and mortality. The breast cancer places a considerable financial, emotional and physical strain on the family and the patient. Despite the advancement in the treatment modalities, it remains a significant burden on the health-care sector ${ }^{5}$.

Current treatment options for localized breast cancer include either modified radical mastectomy (MRM) or breast conserving surgery followed by chemotherapy or radiotherapy 6 . A modified radical mastectomy (MRM) is a procedure in which the entire breast is removed; including the skin, areola, nipple, and most axillary lymph nodes, but the pectoralis major muscle is spared 7 . Breast conserving surgery (BCS) is defined by the surgical procedure that involves excision of the 
cancerous part of the breast while preserving the disease-free part of the breast. BCS consists of the following procedures; lumpectomy, wide local excision, segmental resection, tylectomy, and quadrantectomy ${ }^{8}$.

Many researchers have compared the patient outcomes including the recurrence rate, and the survival rates between the two treatment options; however how these two treatments affect the quality of life of patients who undergo either MMR or BCS has not been explored thoroughly.

The breast cancer surgery can have drastic effect on patient's perception about her body image aside from the associated physical, psychological and emotional affliction which can significantly reduce the quality of life (QoL) of the patient post-surgery subsequently lowering the effectiveness of the treatment as claimed by Rosenberg and Marshall Gold 910 .

The objective of the present study was to assess the quality of life of breast cancer patients who underwent breast conservation surgery compared to those who received modified radical mastectomy in the hopes of determining which of the two treatment modalities causes the least damage to the quality of life of the patient.

\section{METHODOLOGY}

A comparative study was conducted at the Department of General Surgery, Pakistan Institute of Medical Sciences Islamabad from August 2018 to September 2019 for a period of one year. Non-probability consecutive sampling technique was used to enroll patients, with a total of 50 patients who had undergone BCS were put in one group and 166 patients who had received Mastectomy were added in the second group. Patients who had completed their treatment for CA breast (BCS or mastectomy along with adjuvant chemotherapy or radiotherapy) at least 2 months prior to the inception of the study were eligible to participate in the study. Patients who were still under treatment or received treatment (surgery and adjuvant chemotherapy or radiotherapy) $<2$ months ago or $>2$ years ago were excluded from the study. After obtaining approval from hospital ethical review board (reference number 1-1/205/ ERB/SZABMU/240) a written informed consent was obtained from participants presenting in follow up after completion of their treatment (surgery and adjuvant chemo/ radio therapy) to Out Patient Department of General Surgery. Bio data of each participant was obtained by the researcher which included age, gender, profession, stage of disease at diagnosis, type of treatment received and time since treatment.

Participants were interviewed using standardized questionnaire (QOL-CSV) to assess quality of life which included questions about physical well-being, psychological wellbeing, distress factors, fear factors score, social wellbeing and spiritual wellbeing. Questions about how difficult it is to cope as a result of disease and treatment, changes in appearance after treatment, self concept, current level of happiness, how much one feel that one's life is in control, difficulty in remembering or concentrating were asked to assess psychological well-being.

Data thus obtained was entered in SPSS version 20 and frequency with percentages and mean \pm SD were calculated. Tests of statistical significance including chi square and t-test were applied, keeping confidence level 5 and confidence interval to be $95 \%$. Data was then presented in the forms of figure and tables.

\section{RESULTS}

There were a total of 50 participants who had received BCS and 166 who had undergone Mastectomy. A mean age of $50.14 \pm 4.8$ years in BCS group and of $54.7 \pm 6.3$ years in Mastectomy group was observed. Most of the participants receiving Mastectomy presented at stage 3 of the disease $110(66.2 \%)$ whereas in BCS group most participants had stage 2 at presentation $30(60 \%)$. In BCS group 46 (92\%) participants had received treatment less than 6 months ago whereas most of the Mastectomy cases were interview 6 months to 1 year after receiving treatment (table-II).

Amongst the BCS group, physical well-being score was moderate with $80 \%$ participants scoring between 40 and 50 out of 80 . Psychological 
well-being score was even better with majority $(76 \%)$ having a score of $50-60$ out of 80 . Distress of diagnosis and treatment was moderate with none having QoL score more than 17 out of 50 . Fear factor scored moderate with $88 \%$ participants having QoLsscore between 20 and 30. For 98\% respondents Social well-being QoL score

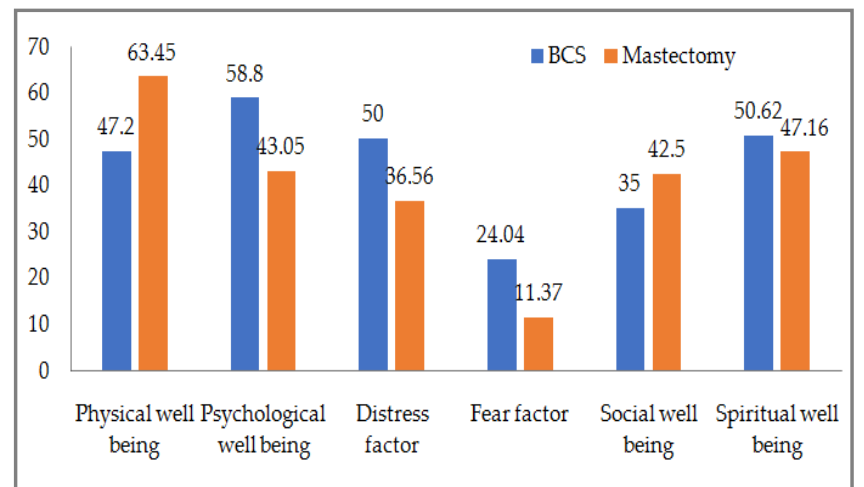

Figure: Comparing QoL of Breast conservation surgery group with Mastectomy group.

was $30-40$ out of 80 . Spiritual well-being score was high with $52 \%$ participants reporting score of more than 50 out of 70 .

In Mastectomy group physical well-being score was high with $41.6 \%$ participants having a score of 61-70 out of 80 . Psychological analysis showed moderate score with most participants
In the current study it has been observed that there was no significant difference observed in the physical symptoms and functional status of participants in both groups. Psychological well-

Table-I: Demographics and clinical characteristics of study participants.

\begin{tabular}{|c|c|c|}
\hline Variable & $\begin{array}{l}\text { Breast Conser- } \\
\text { vation Surgery } \\
\text { Group }(n=50)\end{array}$ & $\begin{array}{c}\text { Mastectomy } \\
\text { Group } \\
(n=166)\end{array}$ \\
\hline \multicolumn{3}{|l|}{ Age (Year) } \\
\hline Mean \pm SD & $50.14 \pm 4.8$ & $54.7 \pm 6.3$ \\
\hline \multicolumn{3}{|c|}{ Marital Status } \\
\hline Unmarried & $2(4 \%)$ & $8(4.8 \%)$ \\
\hline Married & $48(96 \%)$ & $158(95.2 \%)$ \\
\hline \multicolumn{3}{|c|}{ Age at Diagnosis (Year) } \\
\hline Mean \pm SD & $49.30 \pm 5.4$ & $53.9 \pm 3.3$ \\
\hline \multicolumn{3}{|l|}{ Tumor Grade } \\
\hline Grade I & - & - \\
\hline Grade II & $29(58 \%)$ & $92(55.4 \%)$ \\
\hline Grade III & $21(42 \%)$ & $74(44.6 \%)$ \\
\hline \multicolumn{3}{|l|}{ Tumor Stage } \\
\hline Stage I & $3(6 \%)$ & - \\
\hline Stage II & $30(60 \%)$ & $48(28.9 \%)$ \\
\hline Stage III & $7(14 \%)$ & $110(66.2 \%)$ \\
\hline Stage IV & $10(20 \%)$ & $8(4.8 \%)$ \\
\hline
\end{tabular}

being had a better mean value in BCS group however; the difference was not statistically significant. Similarly, fear and distress were almost equ-

Table-II: Mean quality of life scale scores for both Breast conservation group and mastectomy group.

\begin{tabular}{l|c|c|c}
\hline Item & $\begin{array}{c}\text { Breast Conservation } \\
\text { Group (Mean Score) }\end{array}$ & $\begin{array}{c}\text { Mastectomy } \\
\text { (Mean Score) }\end{array}$ & $\boldsymbol{p}$-value \\
\hline Physical wellbeing score & $47.20 \pm 3.97$ & $63.45 \pm 9.64$ & 0.396 \\
\hline Psychological wellbeing score & $58.80 \pm 2.74$ & $43.05 \pm 7.04$ & 0.170 \\
\hline Distress factor score & $50.00 \pm 2.77$ & $36.56 \pm 6.56$ & 0.309 \\
\hline Fear Factor score & $24.04 \pm 2.75$ & $11.37 \pm 8.29$ & 0.537 \\
\hline Social wellbeing score & $35.00 \pm 3.37$ & $42.57 \pm 8.44$ & 0.175 \\
\hline Spiritual wellbeing score & $50.62 \pm 2.96$ & $47.16 \pm 6.27$ & 0.008 \\
\hline
\end{tabular}

(65.1\%) scoring 41-50 out of 90 . Distress levels associated with diagnosis and treatment were high, with most of the participants $(46.4 \%)$ reporting score of $30-40$ out of 50 . Fear factor was moderate with $52.4 \% 11-30$ on a scale of 40 . Social concerns scored moderately with highest number $(42.7 \%)$ of respondents scoring $41-50$ out of 80 . Moderate scoring was observed in Spiritual wellbeing with $68.7 \%$ participants having scored less than 50 out of 70 as shown in figure. ally present in both the groups. The most striking difference was noticed in the social wellbeing of the participants with those receiving BCS reporting better personal relationship, less interference in work, positive feeling regarding sexuality and all these factors contributed in improved quality of life with respect to social outcomes.

There was no comparable difference observed between BCS and Mastectomy group with respect to physical wellbeing $(p=0.396)$, psycho- 
logical wellbeing $(p=0.170)$, distress score $(p=$ $0.309)$, fear factor $(p=0.537)$ or spiritual wellbeing $(p=0.175)$. However significant difference was found in QoL regarding social concerns (personal relationships, sexuality, employment, personal isolation) with $p=0.008$ as shown in table-II.

\section{DISCUSSION}

It is crucial to evaluate the impact of breast conserving surgery on the quality of life compared to mastectomy as it would help the oncologists to decide on the optimum treatment modality for their breast cancer patients ${ }^{11}$.

In a similar study conducted at China ${ }^{12}$, researchers found that patients undergoing conservative surgeries had easier social adjustment, while rest of parameters showed no significance difference. These findings are similar to current study. Wahid et al reported better body image and sexuality in conservative surgeries than after mastectomy in Indonesian population however there was a generalized decrease in social interaction ${ }^{13}$.

Al-Ghazal et al claimed that breast conserving surgery was associated with greater satisfaction and psychosocial well-being in patients compared to mastectomy and reconstruction ${ }^{14}$. Nonetheless, they utilized the hospital anxiety depression scale, the body image scale and the Rosenberg self-esteem scale to compare the two treatment modalities thus explaining the differences between their findings and ours where a quality of Life tool specific for cancer survivor was used.

In Brazil 15 it was reported that there was significant difference in the physical functioning and social interaction scoring with better QoL reported in conservation surgery group, especially in younger population and educated participants. Krzos et al16 reported from Poland that better aesthetic outcomes resulted in improved QoL in terms of psychosocial parameters in all stages of observation.

A meta-analysis conducted in 201917 included 10 studies from US, Singapore, Vietnam and
China also concluded that there was improvement in body image and future perspectives with decreased systemic side effects in BCS group.

In India 18 a cohort conducted over a 1 year long period at Mumbai determined that no significant difference was noticed in long term QoL in mastectomy and breast conservation surgery cases and advocated Mastectomy as a safe and efficient surgical option in Indian population.

Researchers from Texas ${ }^{19}$ reported that difference in QoL amongst BCS and Mastectomy groups become evident long time after surgery only and proper counselling can help improving psychosocial issues of the patients.

In conclusion, the present study suggests that there is no significant difference between Mastectomy and BCS pertaining to the quality of life. Both treatment modalities offer impairment to the quality of life following surgery. Additionally, patients who received the breast conserving surgery were more satisfied with their social wellbeing, reporting better personal relationships, leading to improved quality of life with respect to social outcomes.

\section{CONCLUSION}

BCS showed significant improvement in QoL in terms of social wellbeing of the patient, better psychological wellbeing and comparable physical and spiritual wellbeing in our participants. Although selection of mastectomy or BCS is patient's choice but BCS should only be offered where indicated and to those patients who can understand the choices and are willing for regular follow up. Appropriate counselling must be provided to patients and their families (where and if relevant) before surgery. Support groups and insurance plans can help improve QoL further.

\section{CONFLICT OF INTEREST}

This study has no conflict of interest to be declared by any author.

\section{REFERENCES}

1. Bray F, Ferlay J, Soerjomataram I, Siegel RL, Torre LA, Jemal A. Global cancer statistics 2018: GLOBOCAN estimates of incidence and mortality worldwide for 36 cancers in 185 countries. CA Cancer J Clin 2018; 68(6): 394-424. 
2. Wyld L, Markopoulos C, Leidenius M, Senkus-Konefka E. Breast Cancer Management for Surgeons. Cham: Springer International Publishing; 2018.

3. Athar A. Knowledge, attitude and practices of Pakistani women for early breast cancer detection. Breast 2018; 41(21): 1-5.

4. Qureshi MA, Mirza T, Khan S, Sikandar B, Zahid M, Aftab M, et al. Cancer patterns in Karachi (all districts), Pakistan: First results (2010-2015) from a Pathology based cancer registry of the largest government-run diagnostic and reference center of Karachi. Cancer Epidemiol 2016; 44(1): 114-22.

5. Hunter CP. Epidemiology, stage at diagnosis, and tumor biology of breast carcinoma in multiracial and multiethnic populations. Cancer 2000; 88(S5): 1193-202.

6. Amin AT, Refaat A, Amine M. Loco-Regional Recurrence after Conservative Breast Surgery Followed by Radiotherapy versus Mastectomy Alone for T1-2 and N0-1 under the Umbrella of Modern Adjuvant Chemotherapy. SAJ Cancer Sci 2018; 5(2): 301.

7. Bland KI, Chang HR, Copeland III EM. Modified radical mastectomy and simple mastectomy. InThe Breast 2018; 443-61.

8. Kunkler IH, Williams LJ, Jack WJ, Cameron DA, Dixon JM. Breast-conserving surgery with or without irradiation in women aged 65 years or older with early breast cancer (PRIME II): a randomised controlled trial. Lancet Oncol 2015; 16(3): 266-73.

9. Gold M, Dunn LB, Phoenix B, Paul SM, Hamolsky D, Levine JD, et al. Co-occurrence of anxiety and depressive symptoms following breast cancer surgery and its impact on quality of life. Eur J Oncol Nurs 2016; 20(1): 97-105.

10. Rosenberg SM, O'Neill A, Sepucha K, Miller KD, Dang CT, Northfelt DW, et al. Abstract GS6-05: The impact of breast cancer surgery on quality of life: Long term results from E5103. San Antonio Breast Cancer Symposium [Internet]. San Antonio, Texas: American Association for Cancer Research; 2018. Available from: http://10.1158/1538-7445.SABCS18-GS6-05

11. Howes BH, Watson DI, Xu C, Fosh B, Canepa M, Dean NR. Quality of life following total mastectomy with and without reconstruction versus breast-conserving surgery for breast cancer: A case-controlled cohort study. J Plastic Reconstruct Aesthetic Surg 2016; 69(9): 1184-91.

12. He ZY, Tong Q, Wu SG, Li FY, Lin HX, Guan XX. A comparison of quality of life and satisfaction of women with early-stage breast cancer treated with breast conserving therapy vs. mastectomy in southern China. Supportive Care Cancer 2012; 20(10): 2441-49.

13. Wahid DI, Yarsa KY. Comparison of quality of life for breast conserving surgery and mastectomy In early stage breast cancer In breast cancer survivors community. J Med Sci 2018; 50(1): 18-20.

14. Al-Ghazal SK, Fallowfield L, Blamey RW. Comparison of psychological aspects and patient satisfaction following breast conserving surgery, simple mastectomy and breast reconstruction. Eur J Cancer 2000; 36(15): 1938-43.

15. Veiga DF, Campos FS, Ribeiro LM, Archangelo JI, Veiga FJ, Juliano $Y$, et al. Mastectomy versus conservative surgical treatment: the impact on the quality of life of women with breast cancer. Rev. Bras. Saude Mater. Infant 2010; 10(1): 51-57.

16. Krzos A, Stanisławek A, Jędrych M, Łuczyk M, Ślusarska B. Satisfaction with the Aesthetic Effect and Quality of Life for Women after Breast Conserving Therapy (BCT) - Preliminary Research. Int J Environ Res Public Health 2019; 16(23): 4682.

17. Ng ET, Ang RZ, Tran BX, Ho CS, Zhang Z, Tan W, et al. Comparing quality of life in breast cancer patients who underwent mastectomy versus breast-conserving surgery: A Meta-Analysis. Int J Environ Res Public Health 2019; 16(24): 4970.

18. Deepa KV, Gadgil A, Löfgren J, Mehare S, Bhandarkar P, Roy N. Is quality of life after mastectomy comparable to that after breast conservation surgery? A 5-year follow up study from Mumbai, India. Qual Life Res 2020; 29(3): 683-92.

19. Cohen L, Hack TF, De Moor C, Katz J, Goss PE. The effects of type of surgery and time on psychological adjustment in women after breast cancer treatment. Ann Surg Oncol 2000; 7(6): 427-34. 